\title{
Ovarian Solid Teratoma
}

National Cancer Institute

\section{Source}

National Cancer Institute. Ovarian Solid Teratoma. NCI Thesaurus. Code C7285.

A mature teratoma that arises from the ovary and presents as a large solid mass. It contains multiple cysts that vary in size. Small foci of hemorrhage are also present. 